\title{
Estudio de paisaje en el monte de la Hunde y la Palomera (Ayora, Valencia). Aproximación al valor social del paisaje
}

\author{
Velasco, P. ${ }^{1}$, Vallés-Planells, M. ${ }^{2}$, Galiana, F. ${ }^{2 *}$ \\ ${ }^{1}$ c/ Alginet 11, $1^{\circ}$. 46010. Valencia. Correo electrónico: pabvemen@gmail.com \\ ${ }^{2}$ Universitat Politècnica de València. Departamento de Ingeniería Rural y Agroalimentaria. \\ Camino de Vera s/n, 46022. Valencia. Correo electrónico: convalpl@agf.upv.es
}

*Autor para correspondencia: fgaliana@agf.upv.es

\section{Resumen}

La gestión forestal sostenible determina la forma del manejo de las masas forestales bajo criterios paisajísticos. La sociedad busca en los objetivos de gestión forestal la consideración, cada vez más, de los servicios ambientales y confluye, para este caso, con el marco forestal estratégico de la Comunidad Valenciana que se dirige a la valorización de los servicios del monte. La identificación de ciertos servicios, especialmente culturales, requiere el conocimiento específico y participación de la población.

El análisis constituye la parte de un estudio de paisaje realizado bajo los principios normativos europeos y de la Comunidad Valenciana, a la escala de monte, y que recoge el proceso participativo de los agentes sociales sobre la preferencia de la calidad visual de las diferentes unidades de paisaje y de los servicios culturales del paisaje del monte. A través de una encuesta de paisaje, donde se combinan el uso de cartografías e imágenes representativas de unidades de paisaje, previamente definidas, se localizan las unidades de mayor preferencia o valor social para la población. La finalidad es establecer el marco apropiado de información básica en materia de paisaje para la ordenación y gestión integral del espacio forestal.

Se consiguen, a través del proceso de la participación de la población, resultados de los servicios del monte mediante su percepción y en coherencia con la realidad social actual del monte. Se refleja que el uso del valor social del paisaje, orientando las actuaciones hacia el respeto de los paisajes más valorados por la población, más allá de la calidad visual del paisaje facilitada por la preferencia visual, ofrece una mejor valoración para la gestión futura del monte.

Palabras clave: gestión forestal sostenible, participación pública, preferencia visual, servicios de paisaje, valor social del paisaje. 


\section{Introducción}

El análisis del paisaje no solo contribuye a la interpretación del territorio en los instrumentos de planeamiento y de ordenación regional o municipal, sino también a la gestión de los montes. El manejo de las masas forestales orientado a la gestión forestal sostenible debe incorporar también los criterios paisajísticos.

La sociedad busca en los objetivos de la gestión forestal la consideración, cada vez más, de los servicios ambientales y los servicios de paisaje, en confluencia con los objetivos del marco europeo en materia de paisaje (CE, 2000) y del forestal estratégico de la Comunidad Valenciana (Generalitat Valenciana, 2013) que se dirigen a la valorización de los servicios del monte.

En los estudios de paisaje, el uso del concepto de los servicios de paisaje es más adecuado en comparación al de los servicios ambientales pues incluye la dimensión social del paisaje y la consideración del patrón paisajístico, consecuencia de los procesos naturales y antrópicos, para la provisión de beneficios por la sociedad (Vallés-Planells, et al., 2014).

El concepto del valor social del paisaje está fundamentado en la concepción transaccional de las relaciones entre la sociedad y su entorno (Zube, 1987). Según esta teoría, los seres humanos son participantes activos en el paisaje y como consecuencia le atribuyen significado y valor. Las razones por las que la sociedad valora un paisaje son muy diversas (Brown, 2005). Éstas pueden ser de tipo más instrumental porque le aporta un beneficio directo (por ejemplo: le proporcionan un sustento) o pueden deberse a un beneficio de tipo inmaterial (valor simbólico, estético, recreativo, etc.).

Termorshuizen y Opdam (2009) sugieren que el concepto de "servicios de paisaje" sería más apropiado para permitir la integración de los aspectos naturales y culturales, la consideración de los patrones espaciales y la participación de los agentes o interlocutores, en el contexto de procesos de planificación colaborativa a escala local. En su enfoque, el paisaje no es considerado un sinónimo de ecosistema, ni tampoco un conjunto de ecosistemas, sino que los paisajes son vistos como sistemas espaciales de la ecología humana, que proporcionan una amplia gama de funciones valoradas por los seres humanos por razones económicas, socioculturales y ecológicas. En esta línea, las técnicas de consulta pública asociadas a la obtención del valor social del paisaje pueden desempeñar un papel importante a la hora de identificar los servicios de paisaje, en especial los culturales (Fagerholm et al., 2012).

En este contexto y en el estudio del paisaje para el monte del C.U.P. n. ${ }^{\circ} 154$, denominado La Hunde y La Palomera, situado en el término municipal de Ayora (Valencia) y realizado siguiendo los criterios metodológicos de estudios de paisaje de la Generalitat Valenciana (Generalitat Valenciana, 2006, 2012), se ha profundizado en la valoración de los servicios culturales, mediante un proceso de participación pública, su vinculación con las unidades de paisaje y la relación con los métodos directos tradicionales de obtención de la calidad visual del paisaje. 


\section{Material y métodos}

\subsection{Localización y ámbito}

El monte de la Hunde y La Palomera constituye un patrimonio natural y social para Ayora y Valencia, de donde provienen la mayor parte de sus visitantes. El término situado en la comarca del Valle de Ayora, que ocupa $446.6 \mathrm{~km}^{2}$ y alberga una población de 5438 habitantes $(822<16$ años; 3479 de 16 a 64 años; $1137>64$ años; INE, 2011) tiene en el Pico de la Palomera (1 258. msnm) el punto comarcal más elevado. Es un espacio forestal importante al tratarse de una superficie pública arbolada extensa (4884.7 ha) que contiene paisajes de alta calidad, por lo que es un destino muy frecuentado para las actividades de paseo, acampada y naturalistas.

El origen administrativo del monte proviene de la compra de la finca de La Hunde en el año 1944 y La Palomera en 1966 por el Patrimonio Forestal Español. Ha sufrido un progresivo cambio por las actuaciones silvícolas y de repoblación en las zonas más llanas, a costa del cambio de cultivos de cereal y viña, especialmente entre los años 60 hasta principios de los 90. Sus principales infraestructuras son el coto social de caza, el área recreativa y el campamento de la Fuente de la Cadena, que se realizaron durante este periodo. La gestión de las últimas décadas ha ido encaminada al mantenimiento de la masa forestal y se está, actualmente, en proceso de comenzar actuaciones de aprovechamientos después de una reciente ordenación del monte.

La implantación humana desarrollada se centra en las edificaciones de las Casas de la Hunde, el vivero forestal y el área recreativa de la Fuente de la Cadena. Dos carreteras que cruzan el monte de este a oeste (CV-440 y CV-438), las áreas cortafuegos, pistas abundantes y sendas son los elementos que vertebran el territorio y de mayor afección sobre el paisaje (figura 1).

\subsection{Caracterización del paisaje}

Con la ayuda del análisis visual se delimita un ámbito de estudio ampliado que trasciende los límites administrativos del monte por un alcance de la visibilidad máximo de $12 \mathrm{~km}$. La delimitación de las unidades visuales y la exposición visual, se complementa con la visibilidad del paisaje, determinada por las cuencas visuales, tanto de los principales puntos de observación del área de estudio como de sus principales recorridos escénicos.

La organización del carácter del paisaje se interpreta por medio de la estructura formal del paisaje, establecida previamente a partir de capas de relieve, geomorfología (Gómez, 2009) e hidrografía (Gómez de Barreda, 2011), la cubierta del suelo, obtenida a partir de una capa de cubierta vegetal con base fisionómica (Monzó, 2009), y las infraestructuras y asentamientos.

La evolución del paisaje y conflictos paisajísticos fueron determinados por medio de entrevistas a gestores del monte y representantes de los agentes sociales. El contenido del carácter del paisaje se completa con los recursos paisajísticos o ele- 


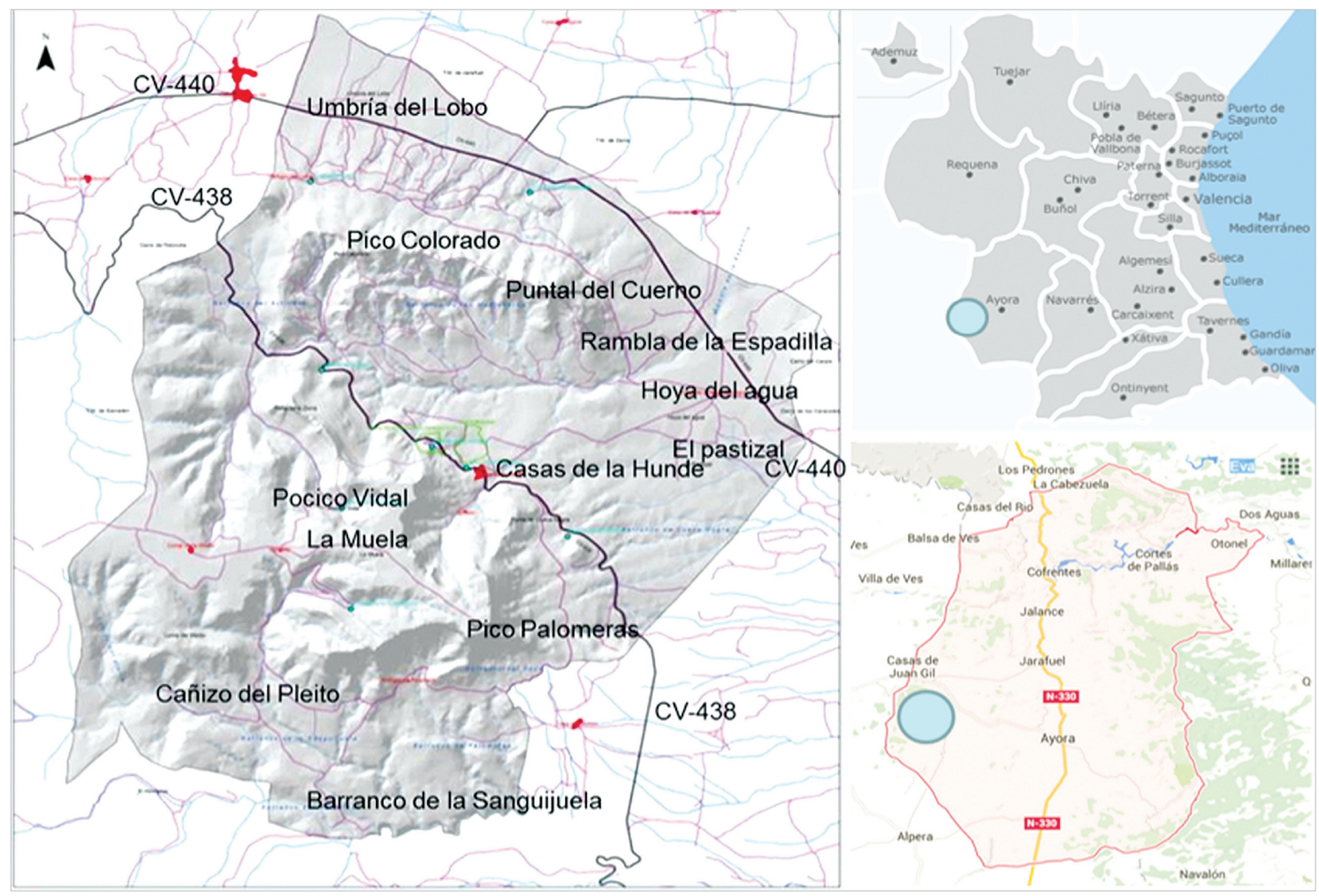

Figura 1. Localización y principales lugares del monte de La Hunde y La Palomera perteneciente a la Comarca de Ayora y a la Provincia de Valencia.

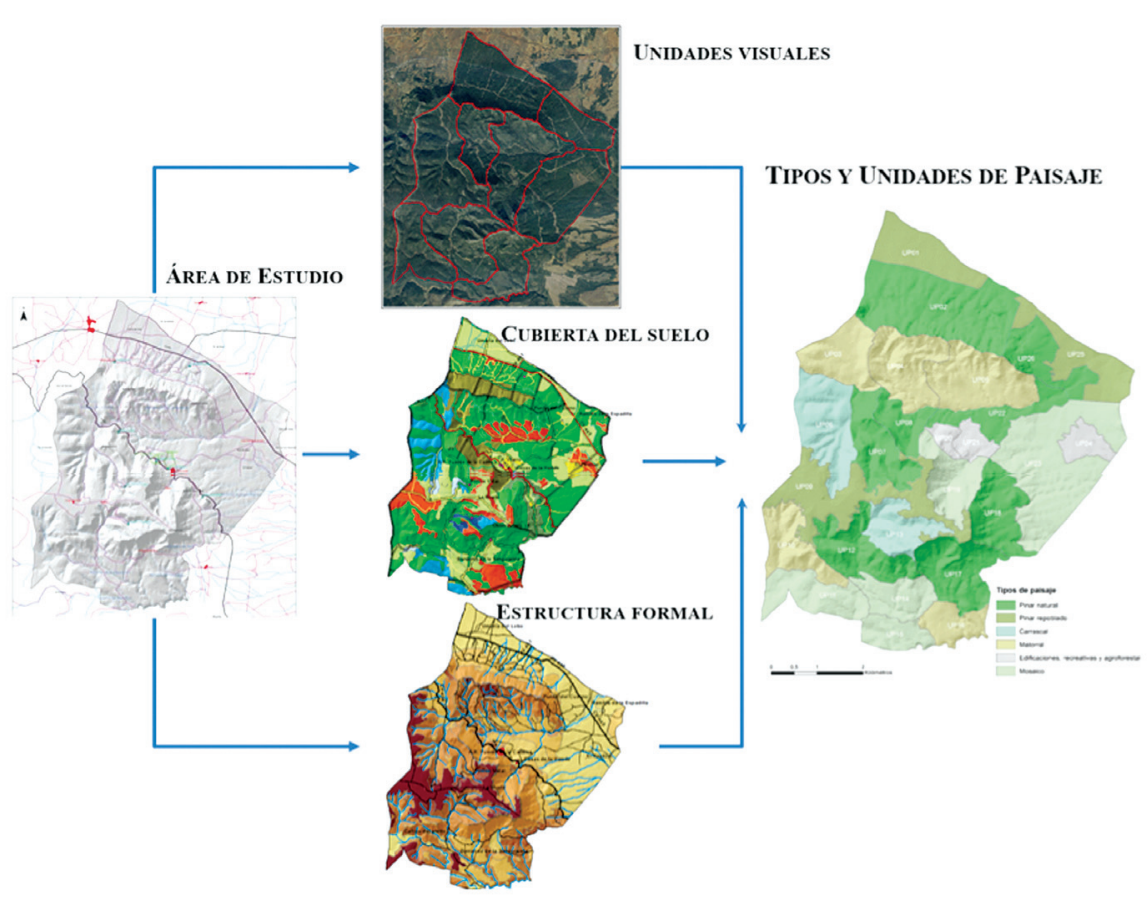

Figura 2. Esquema resumen de la obtención de unidades de paisaje del monte de La Hunde y La Palomera (Ayora, Valencia). 
mentos del paisaje, tanto lineales como puntuales, que lo definen y tienen un valor visual, ecológico o cultural (Generalitat Valenciana, 2012).

La delimitación de tipos de paisaje se lleva a cabo a partir de las unidades visuales y la organización del paisaje, es decir, la cubierta del suelo y la estructura formal del monte (figura 2). En el paisaje forestal mediterráneo de este monte se identifican tres patrones forestales: combinaciones de pinar, de matorral y encinar en terreno montañoso (Generalitat Valenciana, 2012). Se definen seis tipos generales de paisaje que se detallan en la tabla 1, que son la base para la delimitación de las 26 unidades de paisaje (figura 3) definitivas, ajustadas a esta escala y con el objeto de referenciar la valoración social del monte hecha en la participación pública. La tabla 2 caracteriza y diferencia las unidades de paisaje por medio de las proporciones de sus cubiertas.

Tabla 1. Tipos de paisaje definidos a la escala del monte de La Hunde y La Palomera (Ayora, Valencia).

\section{CÓDIGO DE PAISAJE}

TP1

TP2

TP3

TP4

TP5

TP6

\section{CATEGORÍAS DE PAISAJE}

Masas naturales de pinar

Pinar repoblado

Carrascales y zonas con manchas de frondosas

Zonas de predominio de matorrales

Zona recreativa, elementos agroforestales y edificaciones

Mosaico de cubiertas forestales

\subsection{Proceso de valoración pública}

El proceso de participación pública prospecta las opiniones y aspiraciones de la población (Generalitat Valenciana, 2012) cuyo resultado es el valor social del paisaje. La implicación de la población desde el origen del proceso garantiza más transparencia, información útil y actualizada, y la participación en la gestión del monte.

La recogida de la información se realizó a través de un taller de paisaje durante una semana de abril de 2013, habiéndose convocado a la población por carteles en el municipio, información difundida por el ayuntamiento y citas para las entrevistas personalizadas de representantes de los agentes sociales involucrados. Una primera actividad consistió en una encuesta-entrevista de paisaje a través de un mapa de situación, con objeto de formalizar datos por escrito y cartográficos. La información inicial del análisis visual, recursos paisajísticos y unidades de paisaje fue complementada, y se recabó la de los servicios de paisaje y del valor social del paisaje.

Entre los diferentes grupos de servicios -aprovisionamiento, regulación, soporte y culturales (MA, 2003, Haines-Young y Potschin, 2010, Vallés-Planells et al., 2014)-, los encuestados fueron preguntados y requeridos para que señalasen los ser- 
Tabla 2. Cubiertas de las unidades de paisaje en el monte de La Hunde y La Palomera (Ayora, Valencia).

\begin{tabular}{|c|c|c|c|c|c|c|c|c|c|c|c|c|}
\hline \multirow{2}{*}{$\begin{array}{c}\text { CÓDIGO } \\
\text { UP }\end{array}$} & \multirow{2}{*}{ NOMBRE DE LA UNIDAD DE PAISAJE } & \multicolumn{10}{|c|}{ CUBIERTAS DEL SUELO (\%) } & \multirow{2}{*}{$\begin{array}{l}\text { SUP. } \\
\text { (ha) }\end{array}$} \\
\hline & & QR & QRPH & RFHP & $\mathrm{PH}$ & PHPP & $\mathrm{PP}$ & PHPA & $\mathrm{RPH}$ & M & CNF & \\
\hline UP01 & Repoblado umbría del lobo & & & & & & & & 100 & & & 178.71 \\
\hline UP02 & Entorno del barranco del artillero & & 0.5 & & 59.5 & 38.0 & & & & 1.6 & 0.4 & 167.75 \\
\hline UP03 & Pinares de la umbría del lobo & & 25.5 & & 53.4 & 12.8 & 7.3 & & & & 1.1 & 456.48 \\
\hline UP04 & Cara sur del pico colorado & & 0.4 & & 69.1 & 23.1 & & & & 7.3 & & 213,73 \\
\hline UP05 & Loma del Puntal del Cuerno & & & & 51.4 & & 3 & & & 45.6 & & 256.55 \\
\hline UP06 & Encinar del camino al corral de la muela & 6.7 & 53.6 & & 33.4 & & & & 6.2 & & & 237.36 \\
\hline UP07 & Entorno del Pocico Vidal & 8.2 & 3.1 & & 69.2 & & 1.5 & & 11.1 & 6.9 & & 176.07 \\
\hline UP08 & Pinar de rodeno de la fuente de la teja & & & & 7.8 & 89.2 & 0.1 & & 0.5 & 2.4 & & 95.88 \\
\hline UP09 & Muela de Palomeras & & 2.8 & & 8.4 & & & & 45.3 & 43.1 & 0.3 & 303.45 \\
\hline UP10 & Pinar de la cabecera del cañizo del pleito & & & & 91.1 & & & & & 8.9 & & 154.74 \\
\hline UP11 & Encinares del cañizo del pleito & 4.6 & 33.3 & & 33.8 & & & & 26.5 & & 1.8 & 168.54 \\
\hline UP12 & Pinar del camino de la sanguijuela & & & 0.2 & 91.6 & & & & 0.5 & 6.8 & 0.9 & 197.20 \\
\hline UP13 & B. mixto pinar y fron. Fte. de la sanguijuela & & 8.2 & 31.1 & 27.4 & & & & 0.8 & 32.4 & & 131.86 \\
\hline UP14 & Repoblaciones de Palomeras & & & & 63.7 & & & & 63.7 & 11.7 & 0.8 & 126.59 \\
\hline UP15 & Haza del Horcajo & & 29.7 & & 21.7 & & & & 25.2 & 21.7 & 1.6 & 93.99 \\
\hline UP16 & Matorrales del sur & & & & 11.1 & & & & & 88.8 & & 100.62 \\
\hline UP17 & Pinares del barranco de Palomeras & & 0.1 & & 84.4 & & & 3 & 10.6 & 0.8 & 1,1 & 208.79 \\
\hline UP18 & Pinares de cueva negra & & & & 35.7 & & & 54.3 & 6.7 & 0.7 & 2.6 & 178.90 \\
\hline UP19 & Circo de la Hunde & & & & 29.8 & 32.1 & & 10.1 & 12.5 & 15.6 & & 149.48 \\
\hline UP20 & Área recreativa de la Fuente de la cadena & & & & & & & & 100 & & & 31.94 \\
\hline UP21 & Casas y vivero de la Hunde & 4.9 & & & 1.2 & & & & 52.2 & & 41.7 & 55.17 \\
\hline UP22 & Pinar al norte de casas de la Hunde & & & & 91.6 & 8.2 & & & & & 0.3 & 123.45 \\
\hline UP23 & Pinar de los llanos de la hoya del agua & & & & 67.6 & & & & 30.2 & 0.4 & 1.7 & 471.64 \\
\hline UP24 & El pastizal & & & & & & & & & 67.2 & 32.8 & 68.77 \\
\hline UP25 & Repoblado de la Espadilla & & & & 35.6 & & & & 57.5 & 5.5 & 1.4 & 184.15 \\
\hline UP26 & Pinar al este del Puntal del Cuerno & & & & 100 & & & & & & & 150.09 \\
\hline
\end{tabular}

QR: Bosque de Quercus rotundifolia; QRPH: B. mixto de Q. rotundifolia y Pinus halepensis; RFHP: Bosque mixto de Q. rotundifolia, Q. faginea, P. halepensis, P. pinaster; PH: Bosque de P. halepensis; PHPP: B mixto de P. halepensis y P. pinaster; PHPA: B.mixto de P. halepensis y P. pinea; RPH: Repoblaciones de P. halepensis; M: Matorral; CNF: Cultivos/no forestal. 


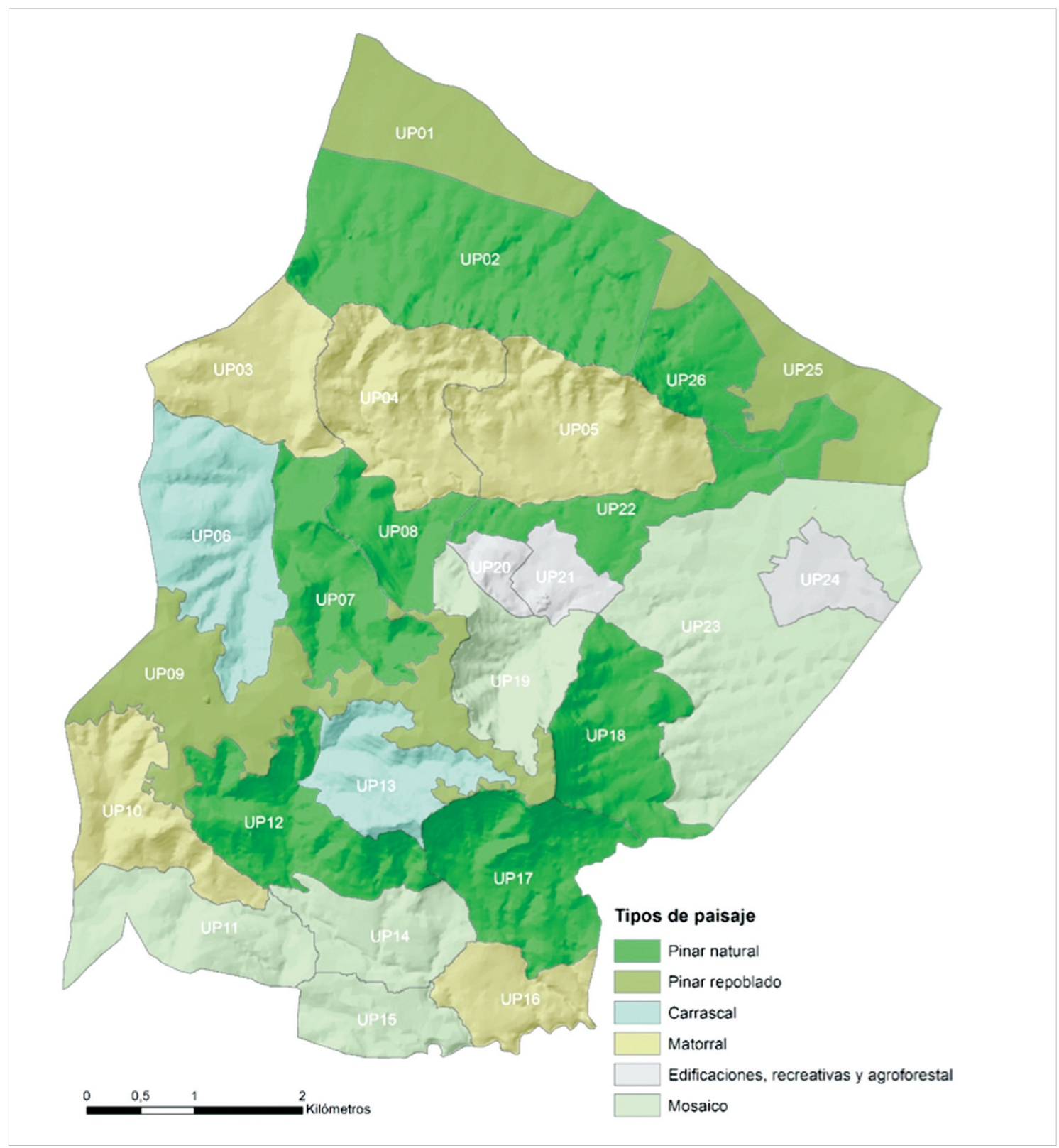

Figura 3. Esquema del mapa resultado de las unidades del paisaje (UP) del monte de La Hunde y La Palomera (Ayora, Valencia) según los principales tipos de patrones de paisaje.

vicios del monte (de aprovisionamiento y culturales; tabla 3), localizándolos en el mapa de situación.

La segunda actividad consistió en una valoración de la calidad visual del paisaje por medio de la técnica de preferencias visuales (MMA, 2006) a partir de 30 imágenes representativas de la zona de estudio y ordenadas según la técnica Q-sort (Generalitat Valenciana, 2010). Se ordenan en cinco clases ajustándose a una distribución normal (3-6-12-6-3) que representa la calidad visual del paisaje por la preferencia de la población. La valoración se complementa con la elección de los tres 
Tabla 3. Relación entre los diferentes servicios ambientales y las correspondientes preguntas de la encuesta del proceso de participación pública en la valoración de los servicios del monte de La Hunde y la Palomera (Ayora, Valencia).

\begin{tabular}{|c|c|c|}
\hline \multicolumn{2}{|r|}{$\begin{array}{l}\text { TIPO DE } \\
\text { SERVICIOS }\end{array}$} & PREGUNTAS \\
\hline \multirow{4}{*}{ 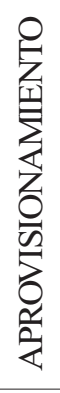 } & Agua & ¿Hace uso de las fuentes del monte? ¿De cuáles? \\
\hline & Material & $\begin{array}{l}\text { ¿Va al monte a recoger setas? ¿A qué zonas? } \\
\text { ¿Recoge plantas aromáticas del monte? ¿En qué zonas? }\end{array}$ \\
\hline & Energía & ¿Recoge leña del monte? ¿En qué zonas? \\
\hline & $\begin{array}{c}\text { Actividades } \\
\text { diarias }\end{array}$ & ¿Trabaja en el monte? ¿Cuál es su actividad? ¿En qué zonas? \\
\hline \multirow{10}{*}{ 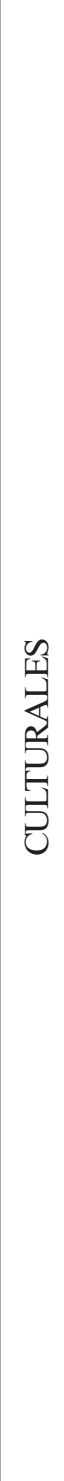 } & Salud & $\begin{array}{l}\text { ¿Hay lugares en el monte donde usted viene para relajarse, } \\
\text { recuperarse del estrés, escapar de la rutina diaria } \\
\text { o estar tranquilo? } \\
\text { ¿Va al monte para hacer ejercicio? ¿A qué zonas? }\end{array}$ \\
\hline & \multirow{4}{*}{$\begin{array}{l}\text { Tiempo } \\
\text { libre }\end{array}$} & $\begin{array}{l}\text { ¿Va al monte para disfrutar del paisaje/vistas? ¿Cuáles son } \\
\text { los lugares más bonitos? ¿Desde qué puntos del monte } \\
\text { se tienen las mejores vistas? }\end{array}$ \\
\hline & & ¿Va al monte para observar orquídeas? ¿En qué zonas? \\
\hline & & $\begin{array}{l}\text { ¿Va al monte para observar la fauna? ¿Qué fauna? } \\
\text { ¿En qué zonas? }\end{array}$ \\
\hline & & $\begin{array}{l}\text { ¿Va al monte para cazar? ¿En qué zonas? } \\
\text { ¿Hace senderismo/ciclismo en el monte? ¿En qué zonas? } \\
\text { ¿Va de acampada al monte? ¿A qué zonas? }\end{array}$ \\
\hline & \multirow{2}{*}{$\begin{array}{l}\text { Realización } \\
\text { personal }\end{array}$} & $\begin{array}{l}\text { ¿Qué elementos le sirven para orientarse en el monte? } \\
\text { ¿En qué zonas se orienta mejor? }\end{array}$ \\
\hline & & $\begin{array}{l}\text { ¿Sabe si alguna zona del monte se utiliza con fines científi- } \\
\text { cos? ¿Cuáles? } \\
\text { ¿Sabe si alguna zona del monte se utiliza con fines didácti- } \\
\text { cos? ¿Cuáles? }\end{array}$ \\
\hline & \multirow{3}{*}{$\begin{array}{l}\text { Realización } \\
\text { social }\end{array}$} & $\begin{array}{l}\text { ¿Va alguna vez a pasar el día al monte con amigos/familia- } \\
\text { res? ¿A qué zonas? }\end{array}$ \\
\hline & & $\begin{array}{l}\text { ¿Cuáles son para usted los elementos/zonas más característi- } \\
\text { cos de este monte? }\end{array}$ \\
\hline & & $\begin{array}{l}\text { ¿Desde cuándo conoce este monte? ¿Hay alguna zona en es- } \\
\text { pecial a la que recuerde haber ido desde su infancia? }\end{array}$ \\
\hline
\end{tabular}


casos que se consideran que mejor representan el paisaje del monte y los tres que deberían conservarse en la situación actual.

\subsection{Valoración social del paisaje}

Como resultado de la primera actividad, encuesta-entrevista de paisaje, se extraen dos tipos de resultados. Por una parte, se calcula el porcentaje de encuestados que identifican cada servicio de aprovisionamiento (agua, recolección de setas, aromáticas, leña) y cultural (relax y tranquilidad, ejercicio físico, disfrute estético/vistas, observación de flora, observación de fauna, senderismo/ciclismo, acampada, orientación, uso científico, uso didáctico, interacción social, identidad, sentido de continuidad) en el monte de La Hunde y La Palomera. Por otra parte, se indica en cada unidad de paisaje la presencia de los servicios descritos y la localización de los lugares frecuentados. En segundo lugar, como resultado de la técnica de preferencia visual, se asigna a cada unidad de paisaje su valor de calidad visual del paisaje por su preferencia visual.

\section{Resultados}

\subsection{Perfil de los encuestados}

El proceso de consulta pública fue realizado por 37 participantes. El mayor porcentaje de encuestados (figura 4) pertenece al grupo de los usuarios (41\%), seguido de los profesionales (24\%) y ecologistas (22\%). Los grupos de desarrollo rural/turismo (8\%) y cazadores/apicultores $(5 \%)$ presentan los porcentajes más bajos. En cuanto a la vinculación con el territorio el $90 \%$ de los participantes son residentes en Ayora, el resto de encuestados son residentes temporales. De estos úl-

\section{Grupos de encuestados en la participación pública}

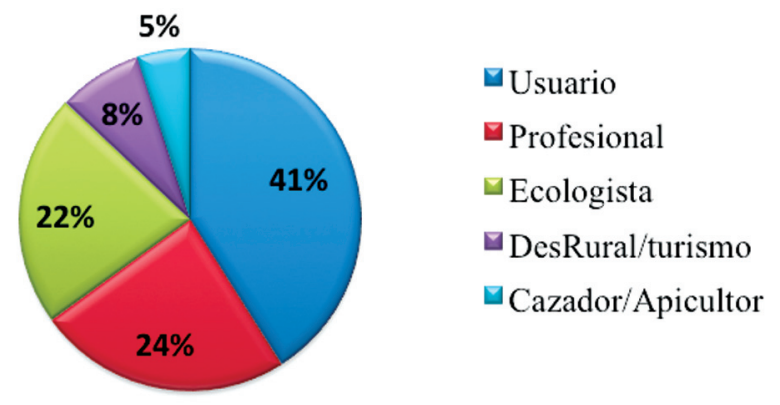

Figura 4. Gráfico de la representación de grupos de encuestados en la participación pública del monte de La Hunde y La Palomera (Ayora, Valencia). 
timos, la mitad pertenecen al grupo de los profesionales y viven temporalmente en Ayora por trabajo, el resto del año viven en pueblos del entorno; la otra mitad son usuarios nacidos en Ayora que viven en Valencia.

En cuanto al rango de edad, más de la mitad de los participantes eran de mediana edad (41 - 60 años). La representación de edades más bajas empieza con el rango de 26 a 40 años con un porcentaje del $24 \%$ frente al 14\% del rango de 61 años en adelante.

\subsection{Servicios de paisaje}

En relación a los servicios de aprovisionamiento (tabla 4), predominan los relacionados con el agua, el $83.8 \%$ de los encuestados hace uso de las fuentes. Se pone de manifiesto que su uso es generalizado, destacando entre ellas la Fuente de la Cadena, situada en el centro del monte (UP20) dentro del área recreativa a la que da nombre.

La recolección de productos comestibles también es importante en el monte de la Hunde y Palomera, el $64.9 \%$ de los encuestados afirma obtener este beneficio del monte, siendo las setas el producto dominante. Entre las especies de hongos se destaca el rebollón (Lactarius deliciosus L.) y en cuanto al lugar de recolección, predominan las zonas llanas de pinar de la Hoya del Agua (UP23), de fácil acceso. El resto de productos son las aromáticas, piñas, madroños y espárragos, estos últimos con bajos porcentajes y una distribución por el monte heterogénea que varía de unos encuestados a otros.

Más de un tercio de los encuestados (40.5\%) trabaja o ha desarrollado parte de su trabajo alguna vez en La Hunde y La Palomera. Este porcentaje es elevado para una participación abierta, pero se explica porque previamente se contactó con representantes de los agentes o grupos de interés muchos de los cuales cumplían esta condición. Entre los trabajos se destaca sobre el resto, los relacionados con incendios forestales, incluyendo el voluntariado. La apicultura presenta un porcentaje muy bajo, porque solo uno de los encuestados se dedica a esta actividad. Por último, el porcentaje de población que recoge leña en el monte (32.4\%) es menor en comparación con el resto de servicios de aprovisionamiento.

Respecto de los resultados de los servicios culturales, la mayor parte de los encuestados percibe este monte principalmente como un lugar para practicar el senderismo $(100 \%)$, disfrutar de las vistas $(97.3 \%)$ y un entorno para la interacción social $(91.9 \%)$.

Dentro del grupo de los servicios culturales relacionados con la salud, el 78.4\% de los encuestados afirman que el monte les aporta tranquilidad y relajación. Principalmente se asocia este beneficio a la Muela y el Pico Palomeras. Destaca también la Fuente de la Cadena, al ser uno de los lugares más accesibles y equipados para su disfrute en familia. El porcentaje es menor, un 35.1\%, si se habla de personas que utilizan el monte para hacer ejercicio. Entre ellas, más de dos tercios hacen senderismo estrictamente como deporte, los restantes ciclismo de montaña y uno de ellos carrera por montaña. Para realizar esta actividad utilizan todo el monte en conjunto, destacando las subidas a la Muela por su desnivel. 
Tabla 4. Frecuencias de los servicios de paisaje resultado del proceso de participación pública para el monte de La Hunde y La Palomera (Ayora, Valencia).

\begin{tabular}{|c|c|c|c|}
\hline \multicolumn{2}{|c|}{$\begin{array}{c}\text { TIPO DE SERVICIOS } \\
\text { Y GRUPOS }\end{array}$} & \multirow{2}{*}{$\begin{array}{c}\text { SUBGRUPO } \\
\text { Fuentes }\end{array}$} & \multirow{2}{*}{$\begin{array}{c}\text { FRECUENCIA \% } \\
83.8\end{array}$} \\
\hline$\stackrel{o}{z}$ & Agua & & \\
\hline 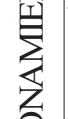 & Material & $\begin{array}{l}\text { Productos forestales } \\
\text { comestibles }\end{array}$ & 64.9 \\
\hline$\frac{0}{5}$ & Energía & Leña & 32 \\
\hline 总 & $\begin{array}{l}\text { Actividades } \\
\text { diarias }\end{array}$ & Trabajo & 40.5 \\
\hline & \multirow{2}{*}{ Salud } & Salud mental & 78.4 \\
\hline & & Ejercicio físico & 35.1 \\
\hline \multirow{13}{*}{ 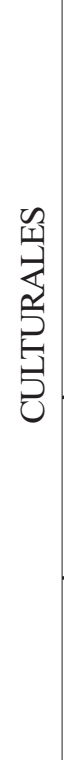 } & \multirow{7}{*}{ Tiempo libre } & Vistas & 97.3 \\
\hline & & Observación de flora & 45.9 \\
\hline & & Observación de fauna & 56.8 \\
\hline & & Caza & 2.7 \\
\hline & & Senderismo & 100 \\
\hline & & Ciclismo & 24 \\
\hline & & Acampada & 51.4 \\
\hline & \multirow{3}{*}{$\begin{array}{l}\text { Realización } \\
\text { personal }\end{array}$} & Orientación & -- \\
\hline & & Recurso científico & 70.3 \\
\hline & & Recurso didáctico & 56.8 \\
\hline & \multirow{3}{*}{ Realización social } & Interacción social & 91.9 \\
\hline & & Identidad del lugar & -- \\
\hline & & Sentido de continuidad & 81.1 \\
\hline
\end{tabular}

En el grupo de servicios asociados al tiempo libre, destaca, junto al disfrute de las vistas y el senderismo, la importancia de la observación de fauna. Más de la mitad de encuestados (56.8\%) dicen haber acudido al monte alguna vez con la intención de observar fauna, frente a la escasa importancia de la caza $(2.7 \%)$. Llama la atención la variedad de animales que van describiendo y comentando (figura 5). También, es remarcable el número de encuestados (45.9\%) que van o han ido alguna vez al monte a observar o fotografiar flora singular. Esto puede deberse a la presencia de endemismos como el narciso trompón, Narcissus pseudonarcisus subsp. radinganorum (Fern. Casas) Mateo et $\mathrm{M}$. B. Crespo, que concentra un mayor número de individuos de la especie en La Hunde y La Palomera (Monzó, 2009). 
Por último, también se pone de manifiesto la importancia de este lugar para la acampada. Más de la mitad de los encuestados (51.4\%) han acampado alguna vez en La Hunde y La Palomera. Esto se debe a que gran parte de los encuestados son ayorinos residentes y conocen el monte desde que nacieron. Todos ellos han acampado en el área recreativa de la Fuente de la Cadena (UP20) y en menor medida en los refugios de la Casa del Lobo y de Palomera.

En relación con los lugares más apreciados por el paisaje y sus vistas, destaca La Muela y, en concreto el Pico Palomeras.

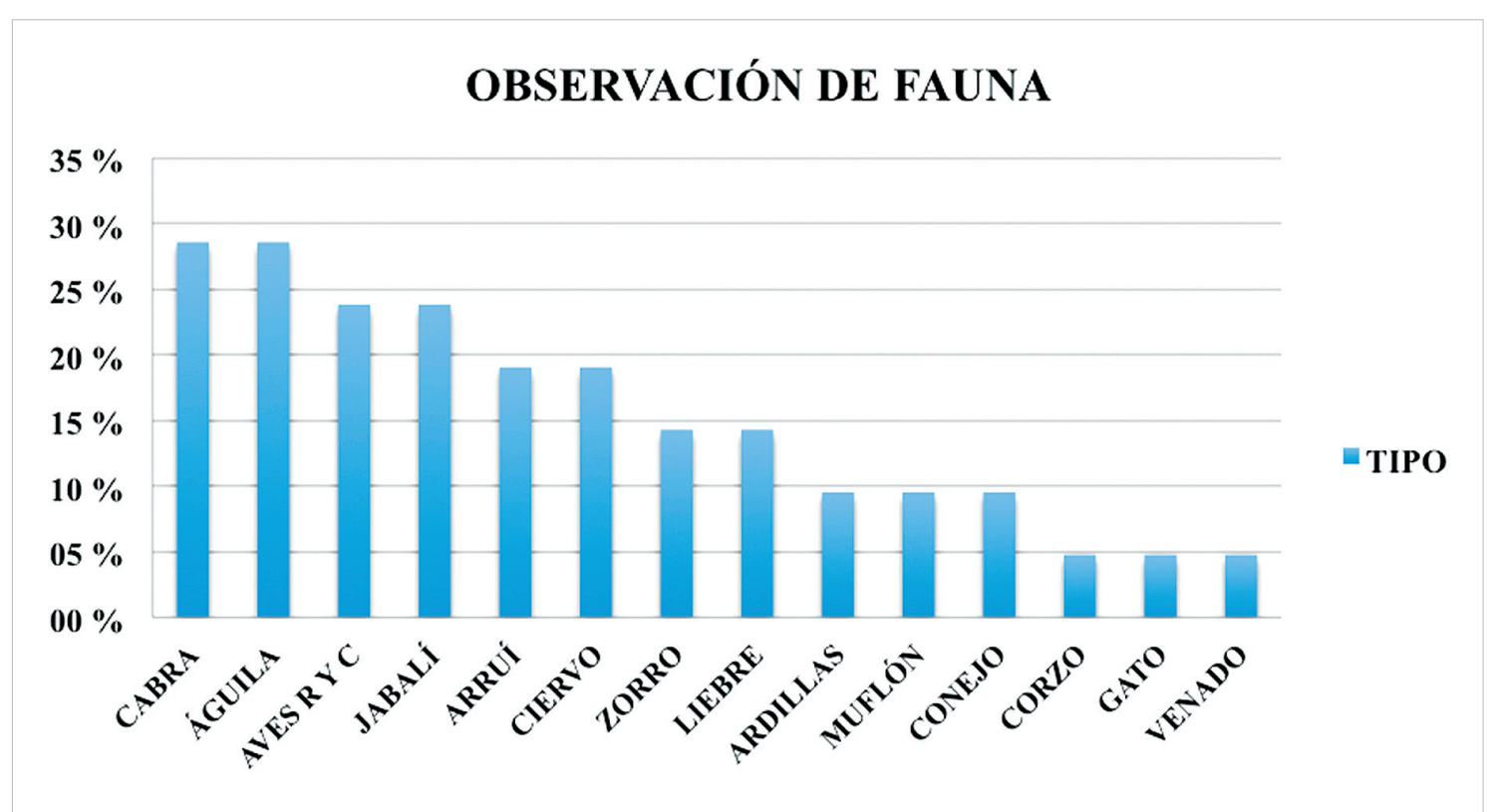

Figura 5. Gráfica de especies de fauna observadas en el Monte de la Hunde y La Palomera (Ayora, Valencia); AVES RYC: Aves rapaces y comunes.

En cuanto al conocimiento de zonas del monte con usos específicos un $70.3 \%$ de encuestados tiene constancia de zonas destinadas a uso científico, destacando el monte en conjunto, estudios de la universidad y las microrreservas de flora. El uso didáctico es menos conocido destacando entre el resto, el campamento del área recreativa de la Fuente de la Cadena utilizado habitualmente por asociaciones juveniles.

Más del 80\% de los encuestados, en su mayoría residentes en Ayora, tiene recuerdos de la infancia en La Hunde y La Palomera (sentido de continuidad). Aparece como elemento central una zona accesible y conocida del monte: el área recreativa de la Fuente de la Cadena. Nombran tanto su fuente como su balsa y, en concreto, el día 18 de julio cuando se acudía allí tradicionalmente para celebrar la fiesta nacional. Estos resultados se repiten en cuanto a pasar el día con amigos o familiares. Por tanto, al referirse al apego al monte, el área recreativa de la Fuente de la Cadena es el elemento principal.

Por último, las preguntas asociadas a los servicios relativos a la orientación y la identidad tienen un sentido más cualitativo y se considera más relevante enten- 


\section{LUGARES MÁS APRECIADOS}

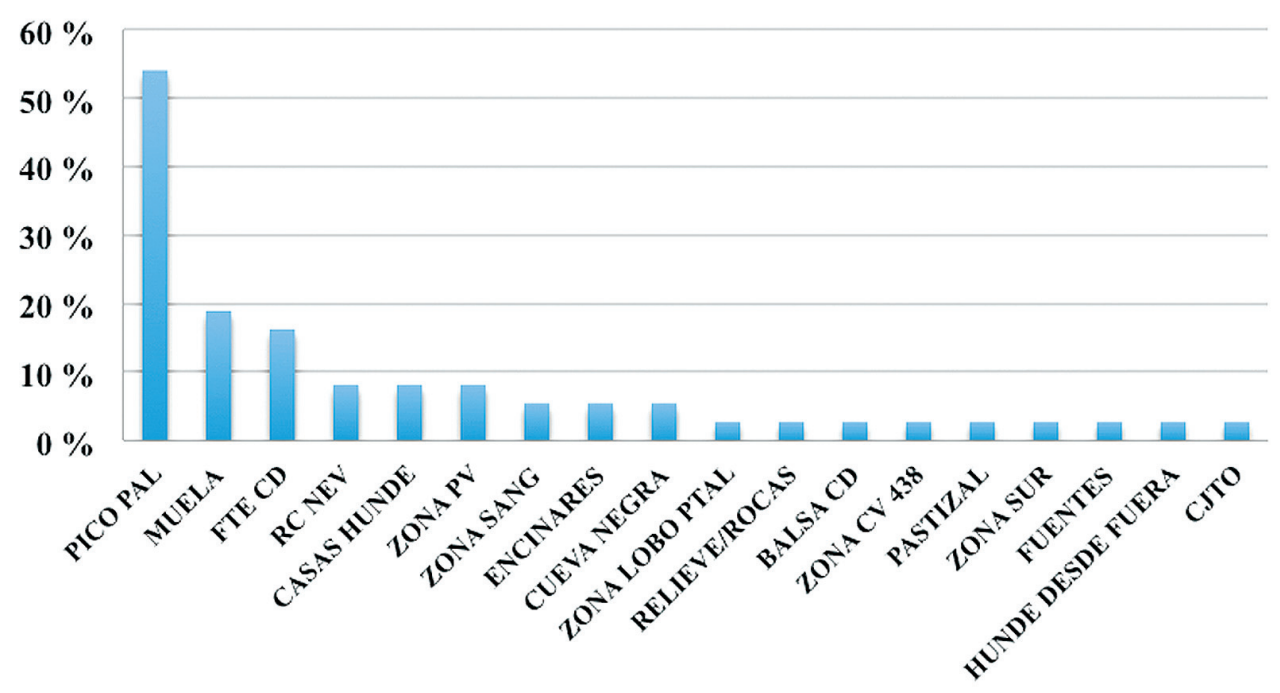

Figura 6. Gráfica de los aspectos y lugares más apreciados en el monte de la Hunde y La Palomera (Ayora, Valencia); PICO PAL: Palomera; FTE CD: fuente de la Cadena; RC NEV: rincón de la Nevera; ZONA PV; zona del Pocico Vidal; ZONA SANG: Sanguijuela; ZONA LOBO PTAL; umbría del Lobo y Puntal del Cuerno; CJTO: conjunto.

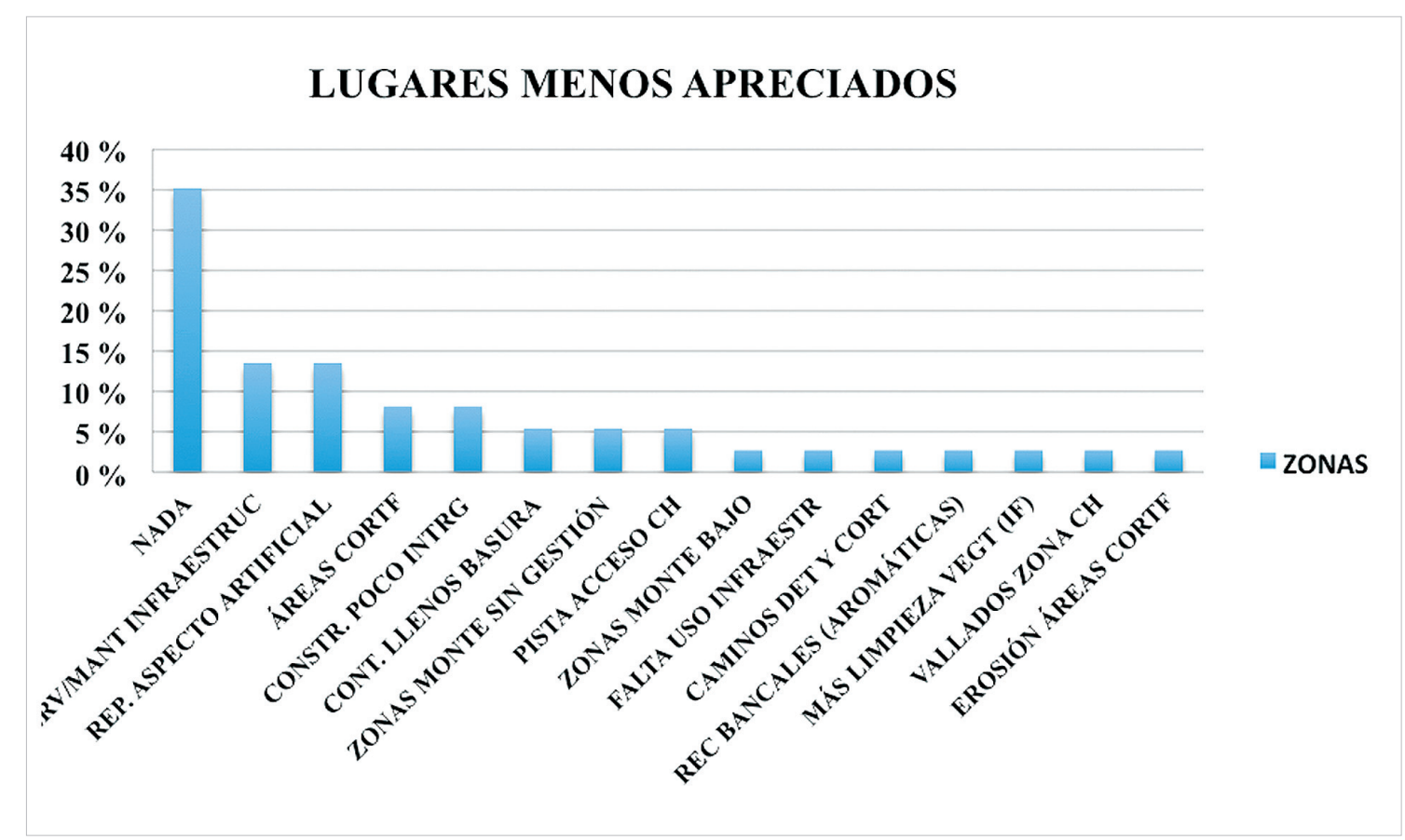

Figura 7. Gráfica de los lugares y de los aspectos de la gestión menos valorados en el monte de La Hunde y La Palomera (Ayora, Valencia); NADA: No hay lugares poco apreciados; REP: Repoblaciones; CONT: contenedores; CH: Casas de la Hunde. 
Tabla 5. Relación servicios, lugares más frecuentados y preferencia visual en las unidades de paisaje del monte de La Hunde y La Palomera (Ayora, Valencia).

\begin{tabular}{|c|c|c|c|c|c|c|c|c|c|c|c|c|c|c|c|c|c|c|c|c|c|c|}
\hline UP & 1 & 2.1 & 2.2 & 3 & 5.1 & 5.2 & 6.1 & 6.2 & 6.3 & 6.5 & 6.6 & 7.1 & 7.2 & 7.3 & 8.1 & 8.2 & $\begin{array}{c}\text { Suma } \\
\text { SA }\end{array}$ & $\underset{\text { SC }}{\text { Suma }}$ & $\begin{array}{c}\text { Suma } \\
\text { servicios }\end{array}$ & $\begin{array}{c}\text { Más } \\
\text { frecuentados }\end{array}$ & $\mathrm{PV}$ & CPV \\
\hline 1 & & & & & & & & & & & & & & & & & 0 & 0 & 0 & & 2.13 & 1 \\
\hline 2 & & $X$ & & $X$ & $X$ & & $X$ & & & & $X$ & & & & & & 2 & 3 & 5 & $X$ & 2.85 & 3 \\
\hline 3 & & & & & & & & & & $X$ & & & & & & & 0 & 1 & 1 & $X$ & 2.25 & 1 \\
\hline 4 & & & & & & & & & & & & & & & & & 0 & 0 & 0 & & 2.25 & 1 \\
\hline 5 & & & & & & & & & & & & & & & & & 0 & 0 & 0 & & 2.86 & 3 \\
\hline 6 & & $X$ & & & & $X$ & $\mathrm{X}$ & & & $X$ & & & & & & & 1 & 3 & 4 & & 3.23 & 5 \\
\hline 7 & $X$ & $X$ & & & & $X$ & $X$ & $X$ & & $X$ & & & & & & & 2 & 4 & 6 & $X$ & 3.51 & 5 \\
\hline 8 & $X$ & & & $\mathrm{X}$ & & & $X$ & $X$ & & $X$ & & & & & & & 2 & 3 & 5 & $X$ & 3.33 & 5 \\
\hline 9 & & $X$ & $X$ & & $\mathrm{X}$ & $X$ & $\mathrm{X}$ & $\mathrm{X}$ & $X$ & $X$ & & $X$ & $X$ & & $\mathrm{X}$ & $\mathrm{X}$ & 2 & 10 & 12 & $X$ & 2.03 & 1 \\
\hline 10 & & & & & & & & & $X$ & & & & & & & & 0 & 1 & 1 & & 2.25 & 1 \\
\hline 11 & & $X$ & & & & & & & $X$ & & & & & & & & 1 & 1 & 2 & & 2.96 & 3 \\
\hline 12 & & $X$ & & & & & & & $X$ & & & & & & & & 1 & 1 & 2 & $X$ & 3.14 & 3 \\
\hline 13 & $X$ & & $X$ & & $X$ & & $\mathrm{X}$ & $X$ & & & & & & & & & 2 & 3 & 5 & $X$ & 2.68 & 3 \\
\hline 14 & & X & & & & & & & $X$ & & & & & & & & 1 & 1 & 2 & & 2.94 & 3 \\
\hline 15 & & & & & & & & & & & & & & & & & 0 & 0 & 0 & & 2.96 & 3 \\
\hline 16 & & & & & & & & & & & & & & & & & 0 & 0 & 0 & & 2.25 & 1 \\
\hline 17 & & $X$ & & & $\mathrm{X}$ & & & & & & $\mathrm{X}$ & & & & & & 1 & 2 & 3 & $\mathrm{X}$ & 3.13 & 3 \\
\hline 18 & $X$ & & & & & & $X$ & & & $X$ & & & & & & & 1 & 2 & 3 & $X$ & 3.37 & 5 \\
\hline 19 & & $X$ & $\mathrm{X}$ & $X$ & $\mathrm{X}$ & & $\mathrm{X}$ & $\mathrm{X}$ & & $\mathrm{X}$ & & & & & & & 3 & 4 & 7 & $X$ & 2.80 & 3 \\
\hline 20 & $\mathrm{X}$ & & $\mathrm{X}$ & & $\mathrm{X}$ & & $\mathrm{X}$ & $\mathrm{X}$ & & $\mathrm{X}$ & $X$ & & & $\mathrm{X}$ & $\mathrm{X}$ & $X$ & 2 & 8 & 10 & $X$ & 3.26 & 5 \\
\hline 21 & $\mathrm{X}$ & & $\mathrm{X}$ & & $\mathrm{X}$ & & $\mathrm{X}$ & $X$ & & $\mathrm{X}$ & & & & & & & 2 & 4 & 6 & $X$ & 3.18 & 3 \\
\hline 22 & & $X$ & $\mathrm{X}$ & $\mathrm{X}$ & & & & & & $X$ & & & & & & & 3 & 1 & 4 & & 2.85 & 3 \\
\hline 23 & & $X$ & & $X$ & & & & & & $\mathrm{X}$ & & & & & & & 2 & 1 & 3 & $X$ & 3.40 & 5 \\
\hline 24 & & & $X$ & & $X$ & & $X$ & & $X$ & & & & & & & & 1 & 3 & 4 & & 3.85 & 5 \\
\hline 25 & & $X$ & & & & & & & & & & & & & & & 1 & 0 & 1 & & 3.38 & 5 \\
\hline 26 & & $X$ & & & & & & & & & & & & & & & 1 & 0 & 1 & & 2.85 & 3 \\
\hline
\end{tabular}

(UP: unidad de paisaje; 1: Agua; 2.1: Recolección de setas; 2.2: Recolección de aromáticas; 3: Leña; 5.1: Relax y tranquilidad; 5.2: Ejercicio físico; 6.1: Disfrute estético/vistas; 6.2. Observación de flora; 6.3: Observación de fauna; 6.5: Senderismo/ciclismo; 6.6: Acampada; 7.1: Orientación; 7.2: Uso científico; 7.3: Uso didáctico; 8.1: Interacción social; 8.2: Identidad; 8:3: Sentido de continuidad; SA: Servicios de aprovisionamiento; SC: servicios culturales; PV: Preferencia visual; CPV: clase de preferencia visual). 
der qué aspectos son los elementos de referencia en el monte, o bien lo caracterizan, respectivamente. Para orientarse en La Hunde y La Palomera, los encuestados utilizan elementos comunes a cualquier otro monte a excepción de la Muela. Se pone de manifiesto la importancia de la Muela como elemento central en el monte. El primer elemento de orientación son los caminos, y puede explicarse por el gran número que existen en el monte donde predominan frente a las sendas. Cabe destacar también la importancia de los puntos altos tanto del monte como de sus alrededores, fuera del ámbito de estudio, pero visibles y útiles para orientarse como puede ser el repetidor de Zarra al este o la Muela de Tortosilla al sur. En cuanto a la pregunta relativa a los elementos que para ellos caracterizan/identifican el monte, hubo una gran variedad de respuestas, combinando tanto aspectos generales como la espesura de su masa forestal o el agua, con elementos concretos de este monte como La Fuente de la Cadena, la Muela y el Pico Palomeras.

\subsection{Lugares más frecuentados y paisajes menos apreciados}

El lugar más frecuentado es la Fuente de la Cadena, seguido, con un porcentaje mucho menor, por el Pico Palomeras. El resto de zonas aparecen con porcentajes mucho más bajos en comparación con las dos zonas principales. Nuevamente, este resultado se puede explicar al ser un lugar accesible, situado en el centro del monte y que genera mucho apego a la población.

Observando la figura 6, se pone de manifiesto que La Hunde es un lugar muy apreciado. La respuesta mayoritaria a la hora de definir los lugares menos apreciados es nula o "nada", es decir, no se considera ningún aspecto o elemento del monte como negativo. Al ser las respuestas de carácter abierto (figura 7), muchos de los encuestados aprovechan para destacar características de la gestión del monte con las que no están de acuerdo como la falta de conservación y mantenimiento de las infraestructuras, el aspecto artificial de las zonas repobladas, las áreas cortafuegos, construcciones poco integradas y la gestión de los residuos. Algunas de las respuestas ponen de manifiesto el conocimiento de la problemática actual de los montes valencianos como es el caso de aquellos encuestados que se quejaban de la existencia de zonas sin gestión forestal alguna.

\subsection{Preferencia visual}

El paisaje más valorado (figura 8, foto 6) es una de las vistas panorámicas desde el Pico Palomeras hacia el noreste, enfocada hacía la masa forestal del pinar de la Hoya del Agua. La desviación típica del análisis de valoración de las imágenes $(\sigma=1,05)$ indica que los resultados para esta fotografía han sido agrupados y que la mayoría de participantes le otorgaban un valor elevado, había acuerdo. También tienen un elevado valor, las fotografias 25 y 2 de la zona de Casas de la Hunde y el área recreativa de la Fuente de la Cadena, que muestran zonas agroforestales con elementos antrópicos.

Los paisajes menos valorados (figura 9) coinciden con las zonas degradadas con matorral de la cara sur de las montañas (fotografías 24 y 27), los pinares repo- 
blados por su aspecto artificial (fotografía 30) y la fotografía 12 que muestra precisamente una parte de un área cortafuegos. Llama la atención como las fotografias 29 y 12 (figura 10) tienen en común la presencia de áreas cortafuegos y presentan valores opuestos. Esto puede deberse a que en la fotografía 29 se combina el área cortafuegos con una vista panorámica hacia el Pico Palomeras que, parece tener más peso a la hora de valorar positivamente la imagen. Para la fotografía 29 la desviación típica es $\sigma=1,05$ y para la 12 es $\sigma=0,87$ por lo que hay más variabilidad en las respuestas de la fotografía más valorada. En cuanto al tipo de paisaje, los más valorados son el tipo 5, instalaciones recreativas y agroforestal, y el tipo 1, pinar natural.

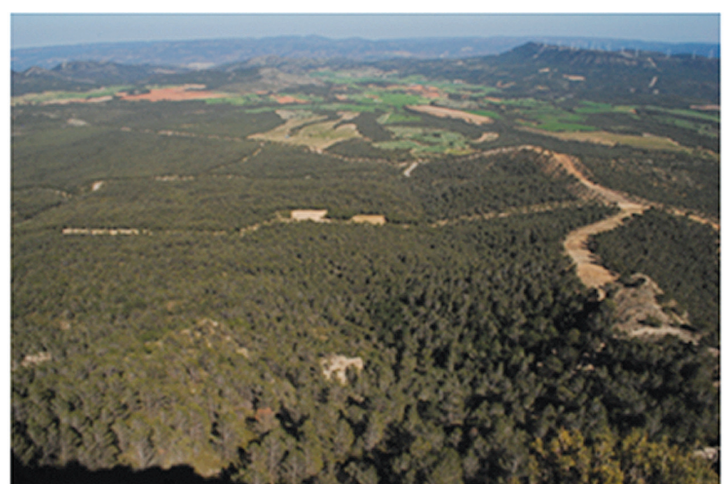

Foto 6 UP: 18 y 23 TP: 1 valor PV: 4.00

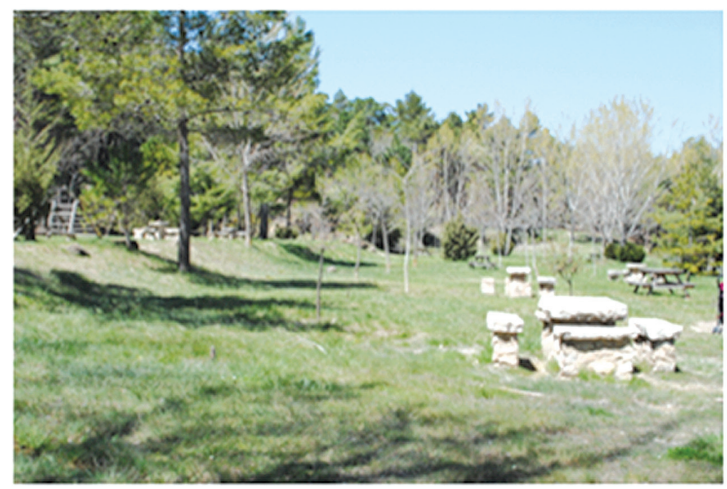

Foto 2 UP: 20 TP: 5 valor PV: 3.67

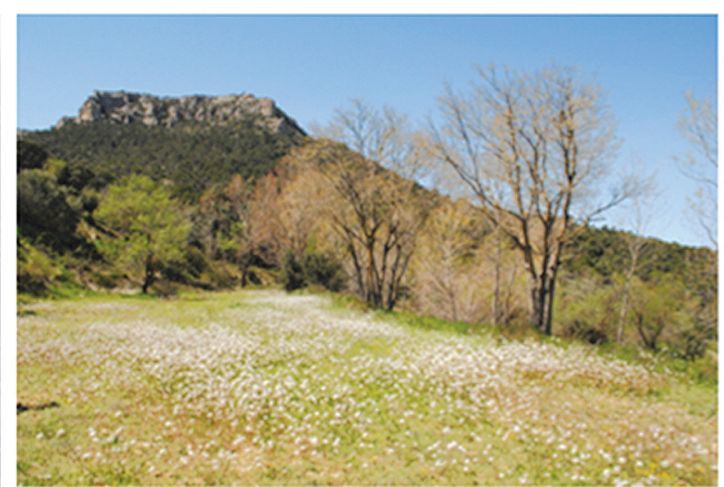

Foto 25 UP: 21 TP: 5 valor PV: 3.85

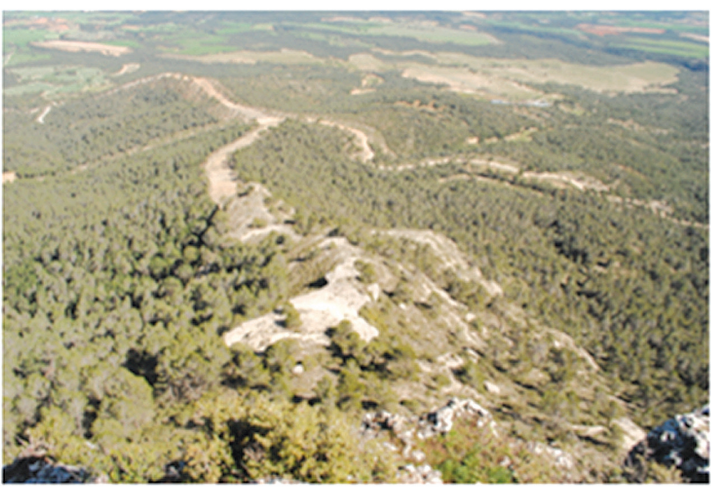

Foto 7 UP: 7 TP: 1 valor PV: 3.51

Figura 8. Las 4 imágenes mejor valoradas y su valor de preferencia visual medio del proceso de participación pública en el monte de La Hunde y La Palomera (Ayora, Valencia).

En cuanto al valor de preferencia visual se observa variabilidad entre grupos de encuestados. Los usuarios y cazadores/apicultores coinciden en paisajes panorámicos desde el Pico Palomeras (fotografías 6 y 7; figura 8), los profesionales y ecologistas prefieren paisajes agroforestales del entorno de Casas de la Hunde, pero con diferencias, los primeros destacan el vivero como elemento característico y singular del monte (fotografía 23) y los segundos un mosaico de paisajes con el per- 


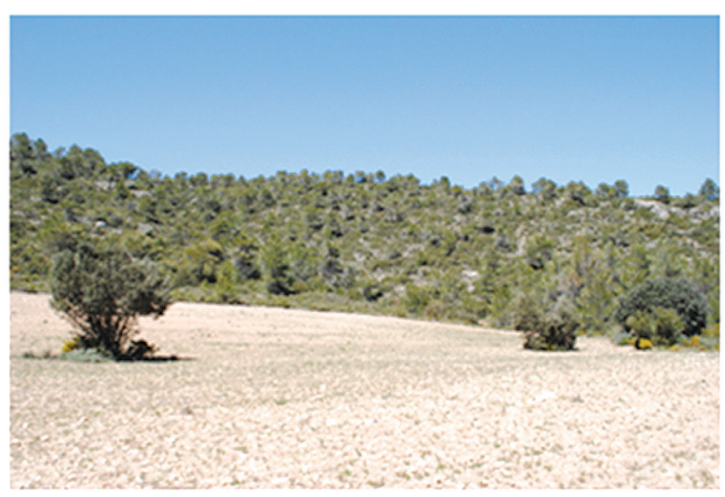

Foto 24 UP: 4 TP: 4 valor PV: 2,28

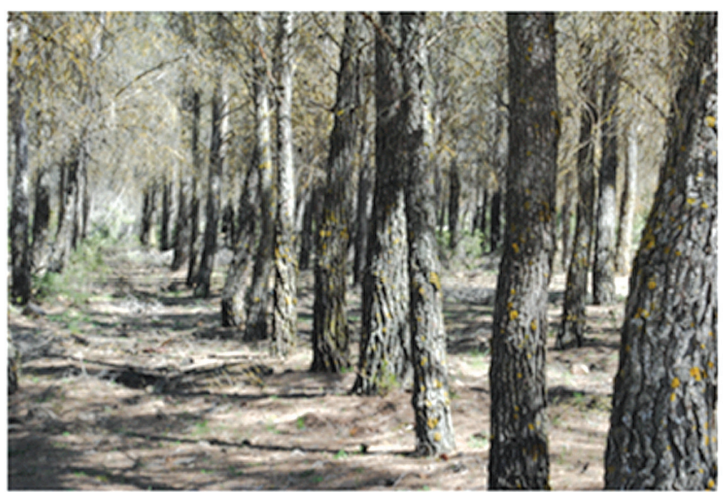

Foto 30 UP: 1 TP: 2 valor PV: 2,13

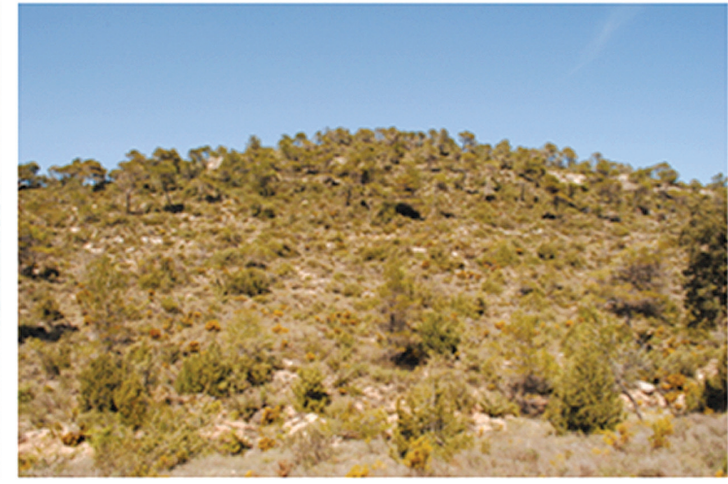

Foto 27 UP: 4 TP: 4 valor PV: 2,13

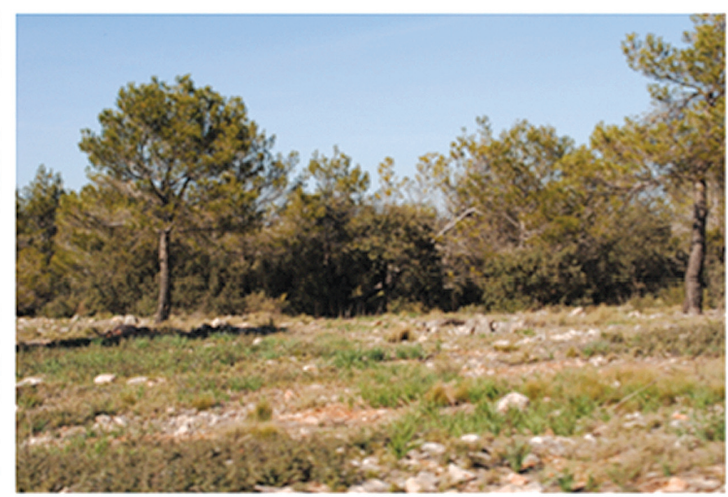

Foto 12 UP: 9 TP: 2 valor PV: 2,03

Figura 9. Las cuatro imágenes peor valoradas y su valor de preferencia visual medio del proceso de participación pública en el monte de La Hunde y La Palomera (Ayora, Valencia).

fil del Puntal del Cuerno de fondo (fotografía 25; figura 11). Finalmente, los encuestados dedicados al desarrollo rural y del sector turístico prefieren el paisaje del área recreativa de la Fuente de la Cadena (fotografía 3; figura 8). Se observan tendencias que coinciden con las características de cada grupo como, por ejemplo, la preferencia de los profesionales por el vivero forestal tan ligado a las repoblaciones tanto de La Hunde y La Palomera como de otros montes públicos de la Comunidad Valenciana.

En los paisajes menos valorados también aparecen diferencias. Vuelven a coincidir usuarios y cazadores/apicultores otorgando el valor menor a un paisaje de quejigo de gran valor ecológico situado en el barranco de la Sanguijuela, esto puede deberse al poco atractivo visual del mismo al encontrarse los quejigos sin hoja en el momento de la fotografía. Los profesionales descartan un paisaje interior de repoblación de pino carrasco que, según ellos, representa la falta de gestión de las repoblaciones. Por último, ecologistas y representantes del desarrollo rural y turismo indican como paisajes menos valorados zonas degradadas de matorral sin arbolado, incluyendo los segundos un pasto cinegético. 


\section{Discusión}

Este trabajo muestra la utilidad que puede tener la combinación de técnicas de preferencia visual asociadas a la valoración de la calidad visual y técnicas de cartografía participativa (Brown, 2005, Fagerholm and Käyhkö, 2009, Tyrväinen, et al., 2007) para estimar las diferentes dimensiones del valor social del paisaje en el contexto de los estudios de paisaje.

Uno de los aspectos más novedosos es la incorporación de la valoración de los servicios de paisaje como herramienta para entender el valor social. Este concepto no sólo ha sido útil para conocer los principales beneficios que percibe la población a nivel de escala de monte, sino también en muchos casos, el lugar concreto que lo proporciona, de modo que cada unidad de paisaje lleva asociados los servicios de paisaje que los encuestados han sido capaces de identificar y localizar.

Se observa que en la mayoría de unidades de paisaje donde se perciben servicios de paisaje, no se dan de forma aislada, sino que confluyen en una misma unidad diferentes servicios. Por ejemplo, en la unidad de paisaje 9 se presentan hasta 12 servicios de paisaje y en la UP20 hasta 10, siendo ambas unidades muy frecuentadas. En el $80 \%$ de las unidades se ha identificado más de un servicio de paisaje y en el $24 \%$, más de 5 servicios (tabla 5).

Tabla 6. Análisis de correlación de Pearson de todas las unidades de paisaje del monte de La Hunde y La Palomera (Ayora, Valencia). SA: Servicios de aprovisionamiento; SC: Servicios culturales; 6.1: Disfrute estético/vistas; CPV: Clase de preferencia visual.

\begin{tabular}{|c|c|c|c|c|c|c|c|}
\hline & & SA & $\mathrm{SC}$ & Servicios & 6.1 & Frecuentados & CPV \\
\hline \multirow{3}{*}{ SA } & Correlación de Pearson & 1 & 0.58 & 0.76 & 0.58 & 0.54 & 0.44 \\
\hline & Sign. (2-colas) & & 0.002 & 0.000 & 0.002 & 0.004 & 0.026 \\
\hline & $\mathrm{N}$ & 26 & 26 & 26 & 26 & 26 & 26 \\
\hline \multirow{3}{*}{$\mathrm{SC}$} & Correlación de Pearson & 0.58 & 1 & 0.97 & 0.75 & 0.57 & 0.17 \\
\hline & Sign. (2-colas) & 0.002 & & 0.000 & 0.000 & 0.002 & 0.412 \\
\hline & $\mathrm{N}$ & 26 & 26 & 26 & 26 & 26 & 26 \\
\hline \multirow{3}{*}{ Servicios } & Correlación de Pearson & 0.76 & 0.97 & 1 & 0.77 & 0.62 & 0.27 \\
\hline & Sign. (2-colas) & 0.000 & 0.000 & & 0.000 & 0.001 & 0.190 \\
\hline & $\mathrm{N}$ & 26 & 26 & 26 & 26 & 26 & 26 \\
\hline \multirow{3}{*}{6.1} & Correlación de Pearson & 0.58 & 0.75 & 0.77 & 1 & 0.54 & 0.44 \\
\hline & Sign. (2-colas) & 0.002 & 0.000 & 0.000 & & 0.004 & 0.023 \\
\hline & $\mathrm{N}$ & 26 & 26 & 26 & 26 & 26 & 26 \\
\hline \multirow{3}{*}{ Frecuentados } & Correlación de Pearson & 0.54 & 0.57 & 0.62 & 0.54 & 1 & 0.21 \\
\hline & Sign. (2-colas) & 0.004 & 0.002 & 0.001 & 0.004 & & 0.301 \\
\hline & $\mathrm{N}$ & 26 & 26 & 26 & 26 & 26 & 26 \\
\hline \multirow{3}{*}{$\mathrm{CPV}$} & Correlación de Pearson & 0.44 & 0.17 & 0.27 & 0.44 & 0.21 & 1 \\
\hline & Sign. (2-colas) & 0.026 & 0.412 & 0.190 & 0.023 & 0.301 & \\
\hline & $\mathrm{N}$ & 26 & 26 & 26 & 26 & 26 & 26 \\
\hline
\end{tabular}


Tabla 7. Análisis de correlación de Pearson de las unidades de paisaje del monte de la Hunde y La Palomera (Ayora, Valencia) excepto las unidades 9 y 25. SA: Servicios de aprovisionamiento; SC: Servicios culturales; 6.1: Disfrute estético/vistas; CPV: Clase de preferencia visual.

\begin{tabular}{|c|c|c|c|c|c|c|c|}
\hline & & SA & $\mathrm{SC}$ & Servicios & 6.1 & Frecuentados & CPV \\
\hline \multirow{3}{*}{ SA } & Correlación de Pearson & 1 & 0.62 & 0.82 & 0.57 & 0.53 & 0.55 \\
\hline & Sign. (2-colas) & & 0.001 & 0.000 & 0.004 & 0.008 & 0.006 \\
\hline & $\mathrm{N}$ & 24 & 24 & 24 & 24 & 24 & 24 \\
\hline \multirow{3}{*}{$\mathrm{SC}$} & Correlación de Pearson & 0.62 & 1 & 0.96 & 0.81 & 0.58 & 0.58 \\
\hline & Sign. (2-colas) & 0.001 & & 0.000 & 0.000 & 0.003 & 0.003 \\
\hline & $\mathrm{N}$ & 24 & 24 & 24 & 24 & 24 & 24 \\
\hline \multirow{3}{*}{ Servicios } & Correlación de Pearson & 0.82 & 0.96 & 1 & 0.80 & 0.62 & 0.62 \\
\hline & Sign. (2-colas) & 0.000 & 0.000 & & 0.000 & 0.001 & 0.001 \\
\hline & $\mathrm{N}$ & 24 & 24 & 24 & 24 & 24 & 24 \\
\hline \multirow{3}{*}{6.1} & Correlación de Pearson & 0.57 & 0.81 & 0.80 & 1 & 0.51 & 0.62 \\
\hline & Sign. (2-colas) & 0.004 & 0.000 & 0.000 & & 0.11 & 0.001 \\
\hline & $\mathrm{N}$ & 24 & 24 & 24 & 24 & 24 & 24 \\
\hline \multirow{3}{*}{ Frecuentados } & Correlación de Pearson & 0.53 & 0.58 & 0.62 & 0.51 & 1 & 0.36 \\
\hline & Sign. (2-colas) & 0.008 & 0.003 & 0.001 & 0.11 & & 0.088 \\
\hline & $\mathrm{N}$ & 24 & 24 & 24 & 24 & 24 & 24 \\
\hline \multirow{3}{*}{ CPV } & Correlación de Pearson & 0.55 & 0.58 & 0.62 & 0.62 & 0.36 & 1 \\
\hline & Sign. (2-colas) & 0.006 & 0.003 & 0.001 & 0.001 & 0.088 & \\
\hline & $\mathrm{N}$ & 24 & 24 & 24 & 24 & 24 & 24 \\
\hline
\end{tabular}

Como era de esperar, existe una correlación entre los servicios de paisaje y la frecuentación del lugar. Esto significa que los lugares más frecuentados son aquellos en los que se perciben más servicios de paisaje. Esta relación es muy similar para los servicios de aprovisionamiento y culturales (tabla 6).

Cuando se analiza la relación existente entre los servicios percibidos y el valor de preferencia visual, se observa que no hay una correlación significativa, con un valor de correlación de Pearson de 0.27 (tabla 6). Analizando los datos, se observa que este hecho puede deberse a la existencia de dos casos concretos (unidades 9 y 25) en los que los valores van en sentidos opuestos al resto de los datos. Este hecho se confirma al repetir el análisis de correlación tras eliminar dichas unidades (tabla 7). Por una parte, la unidad 9, Muela de Palomeras (figura 10; foto 12), la unidad donde más servicios se perciben (12), tiene el mínimo valor de preferencia visual (CVP: 1; Tabla 5). La imagen muestra parcialmente el espacio de cortafuegos que culmina La Muela y se percibe una masa arbolada con poco desarrollo vegetativo propio de la posición topográfica expuesta y de la escasa calidad del suelo. Por otra parte, la unidad 25 ( $f$ igura 10), el repoblado de la Espadilla, tiene el valor máximo de preferencia visual (CVP:5) y sólo se relaciona con un tipo de servicio de paisaje. Aquí la imagen muestra una repoblación que no se percibe como tal, una masa bien desarrollada y el cortafuego permite observar en el fondo escénico la propia Muela de La Palomera. 


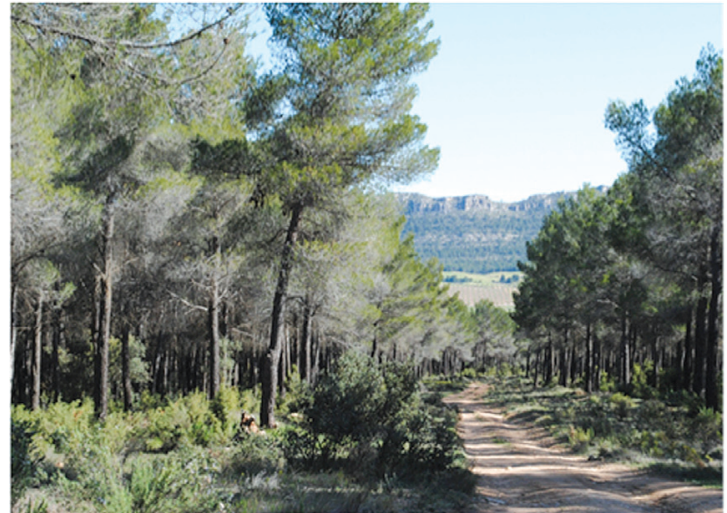

Foto 29 UP: 25 TP: 2 valor PV: 3.38

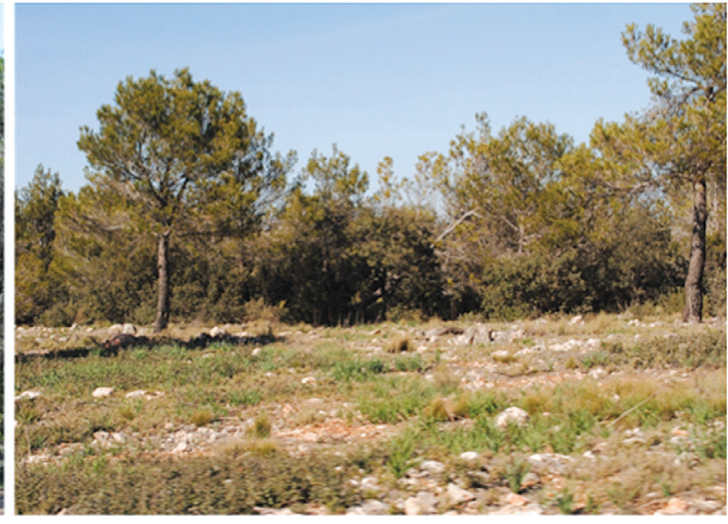

Foto 12 UP: 9 TP: 2 valor PV: 2.85

Figura 10. Imágenes de cortafuegos de valoraciones contrapuestas: Foto: 29, en la unidad de paisaje 25, Tipo de paisaje: 2; Foto: 12, unidad de paisaje: 9, Tipo de paisaje: 2, en el monte de La Hunde y La Palomera (Ayora, Valencia).

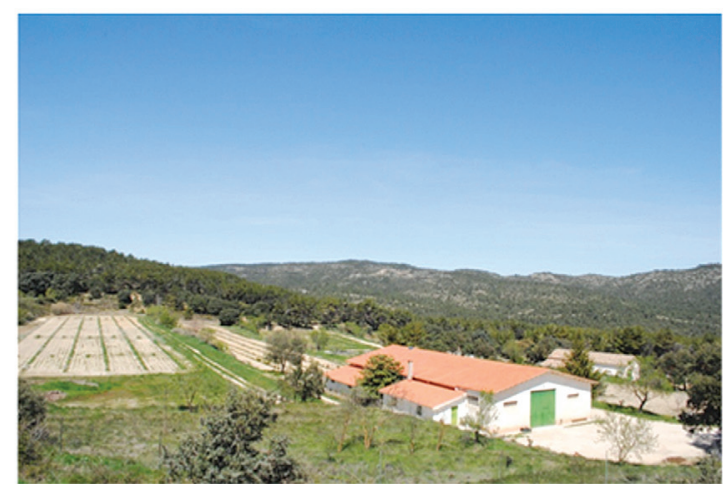

Foto 23 UP: 21 TP: 5 valor PV: 3.26

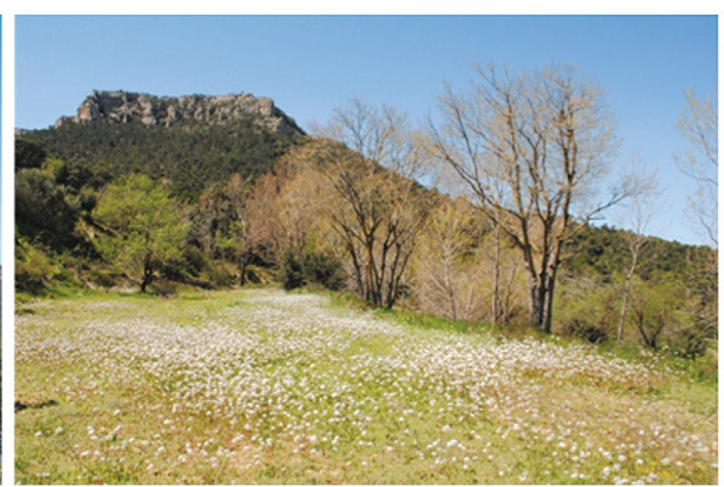

Foto 25 UP: 23 TP: 6 valor PV: 3.40

Figura 11. Imágenes bien valoradas por los profesionales, foto 23 del vivero como elemento singular, y foto 25 mejor valorado por los ecologistas, representando un mosaico de paisaje (UP23) con el fondo del Puntal del Cuerno en el monte de La Hunde y La Palomera (Ayora, Valencia).

Tras eliminar ambas unidades del análisis, se confirma que existe una correlación positiva entre la preferencia visual y los servicios de paisaje en general (0.62) y el servicio cultural asociado al disfrute de las vistas $(0.62 ;$ tabla 7$)$ y la frecuentación no está asociada a la clases de preferencia visual. En consecuencia se aprecia que, la preferencia visual es sólo una parte del valor social, si bien al utilizarse métodos conjuntos se integran aspectos culturales que parten de la información gráfica.

\section{Conclusiones}

En el estudio del paisaje del monte de La Hunde y La Palomera (Ayora, Valencia) se ha procedido a la identificación de los servicios de paisaje de aprovisiona- 
miento y culturales para cada una de las unidades de paisaje previamente definidas.

La estimación del valor social del paisaje ha sido generalmente interpretada a través de las técnicas de preferencia visual, sin embargo, es preciso complementar dicho valor social con la incorporación de los servicios de paisaje. En este sentido, se ha comprobado la utilidad que puede tener la combinación de técnicas de preferencia visual, asociadas a la valoración de la calidad visual de las unidades de paisaje y las técnicas de cartografía participativa, para estimar las diferentes dimensiones del valor social del paisaje a la escala de monte.

La determinación del valor social ha sido útil para conocer los principales beneficios que percibe la población en el ámbito del monte, pero también el lugar concreto que lo proporciona, de modo que cada unidad de paisaje lleva asociados los servicios de paisaje que pueden ser cartografiados y empleados en los planes de gestión y aprovechamiento.

\section{Bibliografía}

Brown, G., 2005. Mapping Spatial Attributes in Survey Research for Natural Resource Management: Methods and Applications. Society and Natural Resources 18, 17-39.

CE, 2000. European Landscape Convention. Council of Europe. Florencia.

Fagerholm, N., Käyhkö, N., 2009. Participatory mapping and geographical patterns of the social landscape values of rural communities in Zanzibar, Tanzania. Fennia 187 (1), 43-60.

Fagerholm, N., Käyhkö, N., Ndumbarob, F., khamisc, M., 2012. Community stakeholders' knowledge in landscape assessments - Mapping indicators for landscape services. Ecological Indicators 18, 421-433.

Generalitat Valenciana, 2006. Decreto 120/2006, de 11 de agosto, del Consell, por el que se aprueba el Reglamento de Paisaje de la Comunitat Valenciana. Consellería de Infraestructuras, Territorio y Medio Ambiente. Generalitat Valenciana. Valencia.

Generalitat Valenciana, 2010. Plan de Acción Territorial de protección de la huerta de Valencia. Propuesta de plan para la información pública. Conselleria de Medi Ambient, Aigua, Urbanisme i Habitatge. Generalitat Valenciana. Valencia

Generalitat Valenciana, 2012. Guía metodológica. Estudios de paisaje. Consellería de Infraestructuras, Territorio y Medio Ambiente. Generalitat Valenciana. Valencia.

Generalitat Valenciana, 2013. Plan de Acción Territorial Forestal de la Comunidad Valenciana. Generalitat Valenciana. Valencia.

Gómez, A., 2009. Estudio geomorfológico del monte de utilidad pública $N^{\circ} 154$ La Hunde y La Palomera situado en el término municipal de Ayora (Valencia). Trabajo final de carrera. Universitat Politècnica de Valéncia.

Gómez de barreda, L., 2011. Estudio hidrológico superficial del monte de utilidad pública de la Hunde y Palomera $\left(n .^{\circ} 154\right)$ en el término municipal de Ayora. Trabajo final de carrera. Universitat Politècnica de Valéncia.

Haines-Young, R.H., y Potschin, M.B., 2010. Proposal for a common international classification of ecosystem goods and services (CICES) for integrated environmental and eco- 
nomic accounting (VI). Report to the European Environment Agency. Department of Economic and Social Affairs Statistics Division, United Nations, Nottingham, UK.

INE, 2011. Censos de Población y Viviendas 2011. Resultados Municipales. http://www. ine.es/dynt3/inebase/index.htm?type=pcaxis \&path=/t20/e244/avance/p02/\&file=pcaxis.

MA (Millennium Ecosystem Assesment), 2003. Ecosystems and Human Well-being: A Framework for Assessment. Island Press, Washington, D.C.

MMA., 2006. Guía para la elaboración de estudios del medio físico. Ministerio de medio ambiente. Madrid.

Monzó, J., 2009. Caracterización de la vegetación y la flora del monte V-1007 de La Hunde y La Palomera en el término municipal de Ayora (Valencia). Trabajo final de carrera. Universitat Politècnica de Valéncia.

Termorshuizen, J.W., y Opdam, P., 2009. Landscape services as a bridge between landscape ecology and sustainable development. Landscape Ecology 24:1037-1052. http://dx.doi. org/10.1007/s10980-008-9314-8

Tyrväinen, L., Mäkinen, K., Schipperijn, J., 2007. Tools for mapping social values of urban woodlands and other green areas. Landscape and Urban Planning 79, 5-19.

Vallés-Planells, M., Galiana, F., Van Eetvelde, V., 2014. A classification of landscapes services to support local landscape planning. Ecology and Society 19 (1), 44. http://dx.doi. org/10.5751/ES-06251-190144

Zube, E.H., 1987. Perceived land use patterns and values. Landscape Ecology 1, 37-45. 